\title{
Effect of respiration and manganese on oxidative
stress resistance of Lactobacillus plantarum
WCFS1 \\ Masayuki Watanabe, ${ }^{1,2}$ Stijn van der Veen, ${ }^{1}$ Hadjime Nakajima ${ }^{2}$ and Tjakko Abee ${ }^{1}$ \\ Correspondence \\ Tjakko Abee \\ tjakko.abee@wur.nl \\ Received 17 May 2011 \\ Revised 16 October 2011 \\ Accepted 19 October 2011 \\ ${ }^{1}$ Laboratory of Food Microbiology, Wageningen University and Research Centre, PO Box 8129, 6700 EV Wageningen, The Netherlands \\ ${ }^{2}$ Milk Science Research Institute, Megmilk Snow Brand Co. Ltd, 1-2 Minamidai 1-chome, Kawagoe, 350-1165 Saitama, Japan \\ Lactobacillus plantarum is a facultatively anaerobic bacterium that can perform respiration under aerobic conditions in the presence of haem, with vitamin $\mathrm{K}_{2}$ acting as a source of menaquinone. We investigated growth performance and oxidative stress resistance of $L b$. plantarum WCFS1 cultures grown in de Man, Rogosa and Sharpe (MRS) medium without and with added manganese under fermentative, aerobic, aerobic with haem, and respiratory conditions. Previous studies showed that $L b$. plantarum WCFS1 lacks a superoxide dismutase and requires high levels of manganese for optimum fermentative and aerobic growth. In this study, respiratory growth with added manganese resulted in significantly higher cell densities compared to the other growth conditions, while without manganese added, similar but lower cell densities were reached. Notably, cells derived from the respiratory cultures showed the highest hydrogen peroxide resistance in all conditions tested, although similar activity levels of haem-dependent catalase were detected in cells grown under aerobic conditions with haem. These results indicate that oxidative stress resistance of $L b$. plantarum is affected by respiratory growth, growth phase, haem and manganese. As levels of haem and manganese can differ considerably in the raw materials used in fermentation processes, including those of milk, meat and vegetables, the insight gained here may provide tools to increase the performance and robustness of starter bacteria.
}

\section{INTRODUCTION}

Lactic acid bacteria such as Lactobacillus plantarum are widely used to produce various types of fermented foods. Several strains of $L b$. plantarum, referred to as probiotics, are used and have been investigated for their potential health properties. Probiotics are defined as live microorganisms that are beneficial for health of the host (Fuller, 1989; FAO/WHO, 2001). Such benefits include reduced diarrhoea symptoms and stimulation of the immune system. Lb. plantarum WCFS1, which was isolated from human saliva, is one of the most widely studied probiotic strains and its genome has been sequenced (Kleerebezem et al., 2003). The function of this strain in the gastrointestinal tract has been investigated extensively (Vesa et al., 2000; Vaughan et al., 2005; Marco et al., 2007) and the host-microbe interaction is also being investigated (Meijerink et al., 2010).

Abbreviations: ETC, electron transport chain; q-PCR, quantitative realtime PCR; ROS, reactive oxygen species; SOD, superoxide dismutase.

A supplementary figure is available with the online version of this paper.
Lb. plantarum is a facultative anaerobe, as it does not contain a complete electron transport chain (ETC) or Krebs cycle. However, it has recently been shown for $L b$. plantarum WCFS1 that under specific conditions, i.e. in the presence of haemin and vitamin $\mathrm{K}_{2}$, an ETC was active, composed of $\mathrm{NADH}$ dehydrogenase, menaquinone (vitamin $\mathrm{K}_{2}$ ) and cytochrome oxidase, using oxygen as a final electron acceptor (Brooijmans et al., 2009b). Growth of $L b$. plantarum under respiratory conditions can result in higher energy production per glucose molecule compared with fermentative growth, thereby improving the formation of biomass. Furthermore, the respiratory growth mode could have a positive impact on the robustness, i.e. stress resistance, of this bacterium, which could be beneficial for its use as a probiotic and starter culture in food fermentations. Lactic acid bacteria contain various stress response mechanisms that protect cells during exposure to adverse environmental conditions (van de Guchte et al., 2002). The adaptive response of $L b$. plantarum WCFS1 to a range of stresses has been investigated, including high temperature (Fiocco et al., 2007), high osmotic pressure (Mille et al., 2005), bile salts (Elkins \& Mullis, 2004), low 
$\mathrm{pH}$ (Ingham et al., 2008) and oxidative stress (Serrano et al., 2007). However, the $\mathrm{Lb}$. plantarum oxidative stress response and survival capacity have not to our knowledge been investigated under respiratory growth conditions.

One of the side effects of growing under respiratory conditions is the possibility that reactive oxygen species (ROS) such as superoxide or hydroxyl radicals are generated due to leakage of electrons from intermediates of the ETC (Kohanski et al., 2007). These ROS can cause significant damage to various cellular structures such as DNA and proteins (Imlay \& Linn, 1988). Most bacteria contain a specific enzyme, superoxide dismutase (SOD), which catalyses the conversion of superoxide to hydrogen peroxide. However, $L b$. plantarum lacks a SOD enzyme and instead this bacterium accumulates high intracellular concentrations of manganese to scavenge superoxide and convert it to hydrogen peroxide $\left(\mathrm{H}_{2} \mathrm{O}_{2}\right)$ during fermentative and aerobic growth (Archibald \& Fridovich, 1981). Indeed, under these conditions $L b$. plantarum WCFS1 requires high concentrations of manganese in the growth medium, e.g. $0.24 \mathrm{mM}$ added manganese in de Man, Rogosa and Sharpe (MRS) medium, to obtain optimal growth conditions (Groot et al., 2005). The impact of manganese on $L b$. plantarum performance during aerobic with haem and respiratory growth conditions has not previously been assessed. Notably, concentrations of manganese in the different niches occupied by $L b$. plantarum, including soil, plant rhizosphere, and foods of plant and animal origin, vary considerably, ranging from $180 \mathrm{nM}$ to $9 \mathrm{mM}$ (Reuther \& Labanauskas, 1966; Chapman, 1966; Labanauskas, 1966; Wang et al., 2008). As the given concentrations reflect total manganese present, the amount of manganese that can be sequestered by $L b$. plantarum can be low in the different environments. $\mathrm{H}_{2} \mathrm{O}_{2}$ can subsequently be decomposed by the action of catalases. Although lactic acid bacteria are generally considered to be catalase-negative, catalase activity has been reported for several species, including members of the genera Lactobacillus, Pediococcus and Leuconostoc (Delwiche, 1961; Knauf et al., 1992; Abriouel et al., 2004). There are two major classes of catalases: true or haemdependent catalase, and manganese-containing catalase or pseudocatalase (Kono \& Fridovich, 1983a, b). Lb. plantarum WCFS1 contains a specific haem-dependent catalase (Kleerebezem et al., 2003; Brooijmans et al., 2009a, b).

Respiratory growth of $\mathrm{Lb}$. plantarum probably results in higher intracellular production of ROS and $\mathrm{H}_{2} \mathrm{O}_{2}$ compared with aerobic growth with haem, and fermentative growth. It is possible that respiratory-grown cells adapt to these oxidizing compounds by inducing oxidative stress mechanisms. Induction of these mechanisms during growth could therefore result in more robust cells that are better equipped to resist the adverse conditions encountered in the gastro-intestinal tract or during preparation or storage of cells for starter cultures. For Lactococcus lactis, it has been shown that growth under respiratory conditions resulted in an increased survival capacity during long-term storage, and resistance was suggested to be linked to reduced intracellular oxygen concentrations (Duwat et al., 2001; Rezaïki et al., 2004). However, Lc. lactis differs significantly from $L b$. plantarum because it contains a functional SOD enzyme but no catalase enzyme.

In this study, we investigated the difference in growth and oxidative stress resistance between respiratory-grown cultures, aerobically grown cultures with and without haem, and fermentatively grown cultures of $L b$. plantarum WCFS1 in MRS medium without and with added manganese. We also investigated whether differences in $\mathrm{H}_{2} \mathrm{O}_{2}$ resistance could be linked to the expression and/or activity of the $L b$. plantarum haem-dependent catalase.

\section{METHODS}

Bacterial strain and culture conditions. $L b$. plantarum WCFS1 was cultivated in MRS broth (de Man et al., 1960), or in modified MRS broth with manganese omitted. These media were recomposed by adding $10 \mathrm{~g}$ peptone from pancreatic digestion of casein (Merck), $8 \mathrm{~g}$ beef extract (Sigma-Aldrich), 4 g yeast extract (Oxoid), $20 \mathrm{~g} \mathrm{D}(+)$-glucose monohydrate (Merck), $2 \mathrm{~g}$ dipotassium hydrogen phosphate (Merck), $1 \mathrm{~g}$ Tween 80 (Merck), $2 \mathrm{~g}$ diammonium citrate (Merck), 5 g sodium acetate (Merck), 0.2 g magnesium sulfate heptahydrate (Merck), with or without $0.04 \mathrm{~g}$ manganese(II) sulfate monohydrate (Merck) to 1 litre of demineralized water. For the induction of ETC activity, haem and vitamin $\mathrm{K}_{2}$ (both Sigma-Aldrich) were added to a final concentration of $10 \mu \mathrm{g} \mathrm{ml}^{-1}$ and $50 \mu \mathrm{g} \mathrm{ml}^{-1}$, respectively (Brooijmans et al., 2009a, b). To prepare pre-cultures, $10 \mathrm{ml}$ MRS was statically incubated overnight at $30{ }^{\circ} \mathrm{C}$. Pre-cultures were washed once with PBS ( $\mathrm{pH}$ adjusted to 7.4 with $\mathrm{HCl}$ ), resuspended in a similar volume of $\mathrm{PBS}$ and inoculated into the different media $(1 \%, v / v)$. Cultures were grown under static (fermentative) or shaking (aerobic) conditions at $30^{\circ} \mathrm{C}$. Aerobic growth was performed by incubation in a shake flask $(100 \mathrm{ml})$ at 200 r.p.m. Cell densities were monitored by measuring $\mathrm{OD}_{600}$.

Assessment of stress survival. The stress survival of exponentialphase cultures $\left(\mathrm{OD}_{600} \sim 0.7\right)$ and stationary-phase cultures $(25 \mathrm{~h})$ was assessed after exposure to $\mathrm{H}_{2} \mathrm{O}_{2}$ and plumbagin. $\mathrm{H}_{2} \mathrm{O}_{2}$ [30\% (w/v) stock solution; Merck] was added to $15 \mathrm{ml}$ cultures to give a final concentration of $0.2 \%(\mathrm{w} / \mathrm{v})$ for exponential-phase cells and $0.5 \%$ $(\mathrm{w} / \mathrm{v})$ for stationary-phase cells. Samples were taken 0, 10, 20 and 30 min after exposure, serially diluted in peptone physiological salt solution $[1 \mathrm{~g}$ neutralized bacteriological peptone (Oxoid) and $8.5 \mathrm{~g}$ $\mathrm{NaCl}$ to 1 litre of demineralized water], and appropriate dilutions were plated on MRS agar plates $[1.5 \%(\mathrm{w} / \mathrm{v})$ bacteriological agar; Merck]. Plates were incubated for $72 \mathrm{~h}$ at $30^{\circ} \mathrm{C}$ and colonies were enumerated. Stress survival of cells was also assessed after exposure to plumbagin. Plumbagin (10 $\mathrm{mg} \mathrm{ml}^{-1}$ stock solution; Sigma-Aldrich) was added to $2 \mathrm{ml}$ cultures to give a final concentration of $10 \mu \mathrm{g} \mathrm{ml}^{-1}$ and the culture was incubated at $30{ }^{\circ} \mathrm{C}$ with shaking at 200 r.p.m. Samples were taken $60 \mathrm{~min}$ after exposure; enumeration was performed as described for $\mathrm{H}_{2} \mathrm{O}_{2}$-stressed cells.

All stress survival experiments were performed in three biologically independent replicates. Means and standard deviations were calculated and statistically significant differences were determined using Student's $t$ tests $(P<0.05)$.

Catalase activity absorbance assay. The catalase activity absorbance assay was performed as described previously (den Besten et al., 2009). Briefly, cells were washed in PBS and then diluted $(1: 10, \mathrm{v} / \mathrm{v})$ in $\mathrm{PBS}$ supplemented with $\mathrm{H}_{2} \mathrm{O}_{2}$ (final concentration, $40 \mathrm{mM}$ ). The decrease in absorbance at $240 \mathrm{~nm}$ was measured over time at $30{ }^{\circ} \mathrm{C}$ 
with a spectrophotometer (Spectramax Plus 384; Molecular Devices). One unit of catalase activity was defined as a decrease in the absorbance at $240 \mathrm{~nm}$ of 1 unit $\mathrm{min}^{-1}$. The rate of decrease for each sample was corrected for the amount of cells added to the assay buffer (absorbance at $600 \mathrm{~nm}$ and the assay dilution factor, as cell suspensions were diluted $1: 10$ when they were exposed to $\mathrm{H}_{2} \mathrm{O}_{2}$ ). For all experimental conditions, three biologically independent replicates were performed.

RNA isolation. Total RNA was isolated from the unstressed cultures grown under different conditions. Cells were pelleted by centrifugation $\left(15000 \mathrm{~g}, 30 \mathrm{~s}, 4^{\circ} \mathrm{C}\right)$. The cell pellet was resuspended in $1 \mathrm{ml}$ TRI Reagent (Ambion), snap-frozen in liquid nitrogen, and stored at $-80{ }^{\circ} \mathrm{C}$ until use. Frozen samples were thawed, transferred to Lysing MatrixB tubes (MP Biochemicals) and homogenized twice for $2 \mathrm{~min}$ at speed 6.0 in a FastPrep-24 instrument (MP Biochemicals). RNA isolation was performed as described in the TRI Reagent manufacturer's protocol. A DNase treatment was performed on the RNA samples using TURBO DNase (Ambion), and the DNase was inactivated with the DNase inactivation agent (Ambion). After this treatment, $10 \mu \mathrm{l}$ sodium acetate solution (3 M, pH 5.2) and $250 \mu \mathrm{l}$ $96 \%$ (v/v) ethanol were added to $100 \mu \mathrm{l}$ RNA and samples were stored at $-80{ }^{\circ} \mathrm{C}$ overnight. RNA was pelleted and washed with $70 \%$ $(\mathrm{v} / \mathrm{v})$ ethanol. Finally, RNA was dissolved in $50 \mu \mathrm{l}$ nuclease-free water. Isolated RNA was quantified and the quality was checked by measuring the absorbance at 260 and $280 \mathrm{~nm}$ on an Eppendorf biophotometer. RNA isolations were performed in two biologically independent replicates.
cDNA synthesis and quantitative real-time PCR (q-PCR). Firststrand cDNA synthesis was performed with Superscript III Reverse transcriptase (Invitrogen) following the manufacturer's protocol, using $2 \mu \mathrm{g}$ total RNA for each sample. q-PCRs were performed on a 7000 sequence detection system (Applied Biosystems) and analysed with 7000 system SDS software. The reactions contained $10 \mu \mathrm{l} 2 \times$ SYBR green PCR Master Mix (Applied Biosystems), $1 \mu \mathrm{l}$ of each primer (16S rRNA-fwd TGATCCTGGCTCAGGACGAA and 16S rRNA-rev TGCAAGCACCAATCAATACCA for 16S rRNA, and kat-fwd TGAAAACGACATGGGGGAAT and kat-rev TTTCACCGGCAACTTGTGAG for $k a t$ ), $6 \mu \mathrm{l}$ water and $2 \mu \mathrm{l} \mathrm{cDNA}$. For each primer set a calibration curve was generated to calculate the efficiency of the PCRs. Expression of the kat target gene was normalized using $16 \mathrm{~S}$ rRNA as internal standard. q-PCR experiments were performed in two independent experiments using two replicates for each sample.

\section{RESULTS}

\section{Effect of manganese and ETC on growth of $L b$. plantarum WCFS1}

To investigate the effect of manganese and oxygen utilization on the growth performance of $L b$. plantarum WCFS1, growth experiments were performed in MRS broth with and without added manganese under the following conditions:
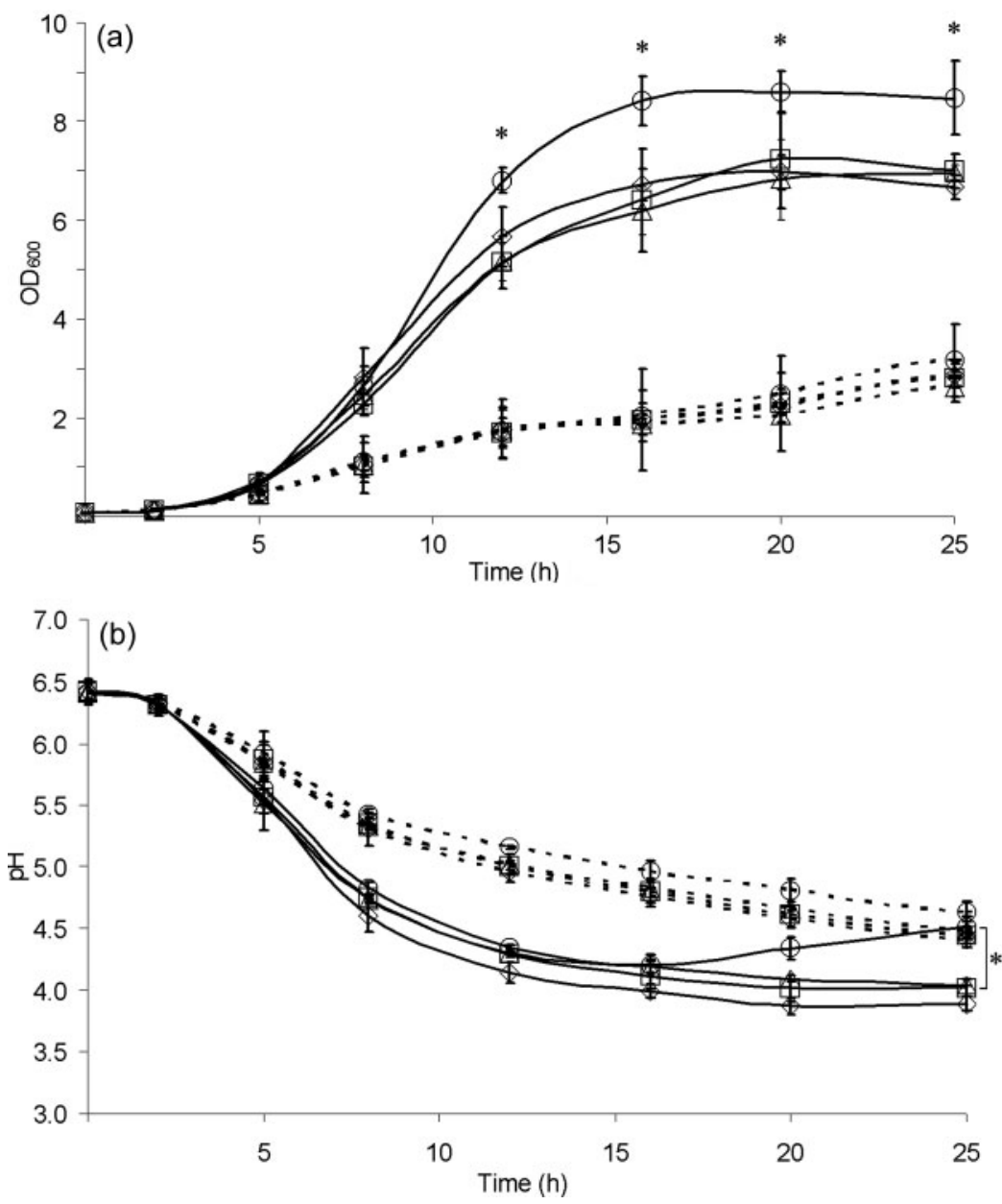

Fig. 1. Effect of oxygen utilization and manganese on the growth performance of $L b$. plantarum WCFS1. The graphs show growth (a) and acidification $(\mathrm{pH})(\mathrm{b})$ of Lb. plantarum WCFS1 in MRS medium with (solid lines) and without (dashed lines) added manganese under fermentative $(\diamond)$, aerobic $(\square)$, aerobic with haem $(\triangle)$ and respiratory $(\bigcirc)$ growth conditions at $30{ }^{\circ} \mathrm{C}$. *, Significantly different from values for all other conditions with and without added manganese $(P<0.05, t$ test). 
fermentation (static; micro-anaerobic), aerobic (shaking), aerobic (shaking) with haem, and respiration (shaking with haem and vitamin $\mathrm{K}_{2}$ ) (Fig. 1). With added manganese no significant differences in growth between the four growth conditions were observed in the early exponential phase (up to $8 \mathrm{~h}$ ) (Fig. 1a). However, from $12 \mathrm{~h}$ onwards, the cell density of the respiratory-grown culture was significantly higher than the those of the other cultures $(P<0.05, t$ test). The mean $( \pm \mathrm{SD})$ final cell densities $\left(\mathrm{OD}_{600}\right)$ after $25 \mathrm{~h}$ of growth for the fermentative, aerobic, aerobic with haem, and respiratory growth conditions were $6.55 \pm 0.03,6.79 \pm 0.66$, $6.67 \pm 0.26$, and $8.50 \pm 0.29$, respectively, with only the last being significantly different from the others.

Growth of $L b$. plantarum WCFS1 is associated with a decrease in $\mathrm{pH}$ of the medium, and a similar decrease in $\mathrm{pH}$ was observed for all growth conditions up to $16 \mathrm{~h}$ (Fig. 1b). However, $\mathrm{pH}$ during respiratory growth then increased, which resulted in a significantly higher $\mathrm{pH}$ after $25 \mathrm{~h}$ for the respiratory-grown culture $(\mathrm{pH} 4.45 \pm 0.11)$ compared with the fermentative $(\mathrm{pH} 3.87 \pm 0.07)$, aerobic $(\mathrm{pH} 3.97 \pm 0.09)$, and aerobic with haem conditions $(\mathrm{pH} 3.99 \pm 0.09)(P<0.05, t$ test $)$. The increase in $\mathrm{pH}$ for the respiratory growth culture might be explained by the conversion of lactate to acetate after glucose depletion, as observed previously for Lc. lactis (Gaudu et al., 2002).
To investigate the role of manganese in the different growth conditions, cultures were grown in MRS broth without added manganese. No differences in growth (Fig. 1a) or $\mathrm{pH}$ (Fig. 1b) between the four growth conditions were observed, but the cultures grown without added manganese reached a lower cell density than cultures with added manganese $(P<0.05, t$ test $)$. These results extend earlier observations with $L b$. plantarum that showed a requirement for high concentrations of manganese to reach optimum growth under fermentative and aerobic without haem conditions (Archibald \& Duong, 1984).

\section{Effect of manganese and ETC on $\mathrm{H}_{2} \mathrm{O}_{2}$ resistance}

To investigate the effect of manganese and oxygen utilization on the resistance to oxidative stress, exponential- and stationary-phase cells of cultures grown in MRS with and without added manganese were exposed to $\mathrm{H}_{2} \mathrm{O}_{2}$ (Figs 2 and 3). Exponential-phase cells from the respiratory-grown culture grown in MRS with manganese showed higher survival after exposure to $0.2 \%(\mathrm{w} / \mathrm{v})$ $\mathrm{H}_{2} \mathrm{O}_{2}$ for 10 and 20 min compared with exponential-phase cells of the fermentative, aerobic and aerobic with haem cultures $(P<0.05, t$ test) (Fig. 2a). Furthermore, higher survival of stationary-phase cells from both the respiratory and aerobic with haem cultures grown in MRS with

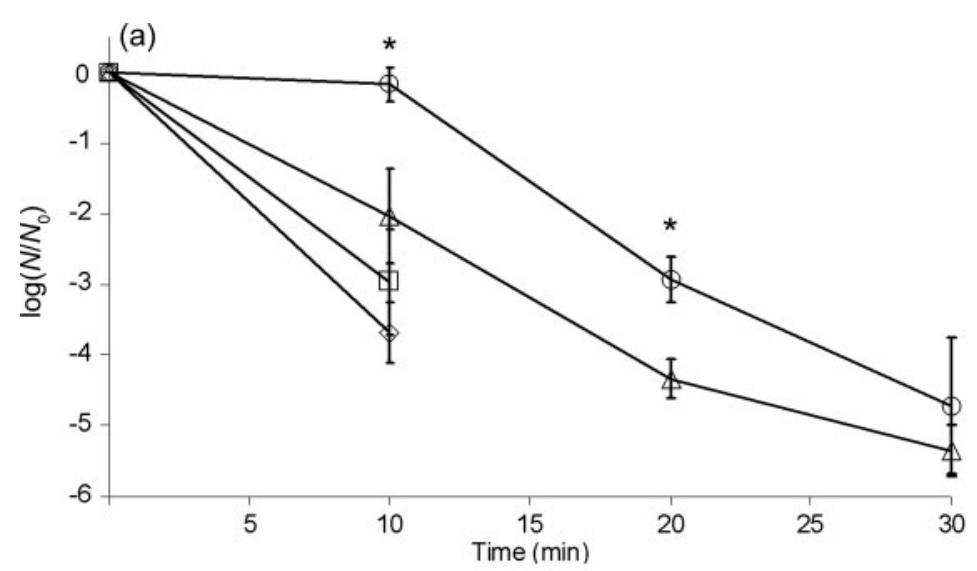

(b)

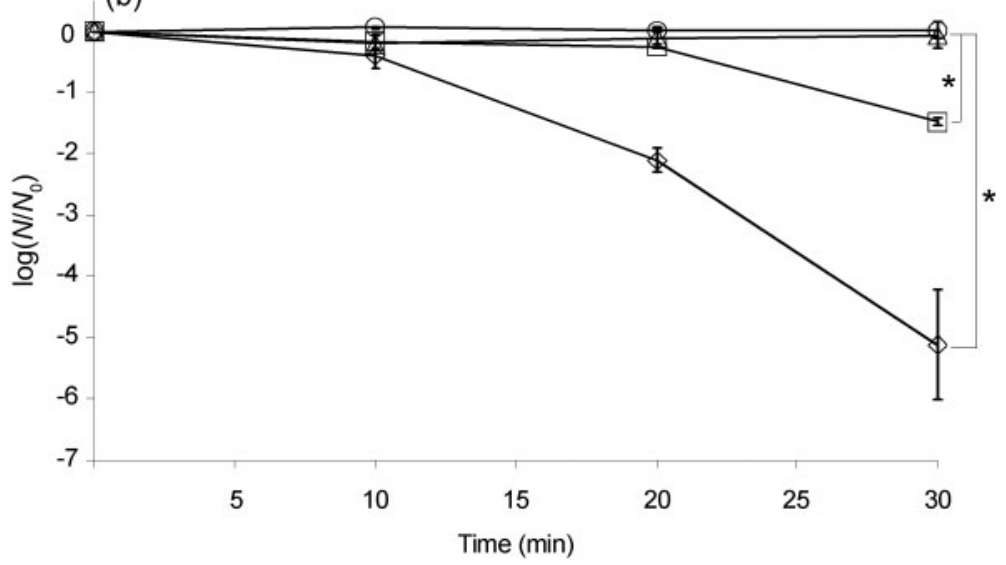

Fig. 2. Effect of oxygen utilization on $\mathrm{H}_{2} \mathrm{O}_{2}$ resistance of $L$ b. plantarum WCFS1 grown in MRS medium with added manganese. The graphs show the survival of exponential-phase (a) and stationary-phase (b) cells grown under fermentative $(\diamond)$, aerobic $(\square)$, aerobic with haem $(\triangle)$ and respiratory $(\bigcirc)$ conditions at $30{ }^{\circ} \mathrm{C}$ after exposure to $0.2 \%(\mathrm{w} / \mathrm{v}$, exponential phase) or $0.5 \%$ (w/v, stationary phase) $\mathrm{H}_{2} \mathrm{O}_{2}$. Samples were taken at $0,10,20$ and $30 \mathrm{~min}$, and c.f.u. $\mathrm{ml}^{-1}$ were counted and expressed as $\log \left(N / N_{0}\right)$. *, Significantly different from values for all other conditions $(P<0.05, t$ test $)$. 
(a)

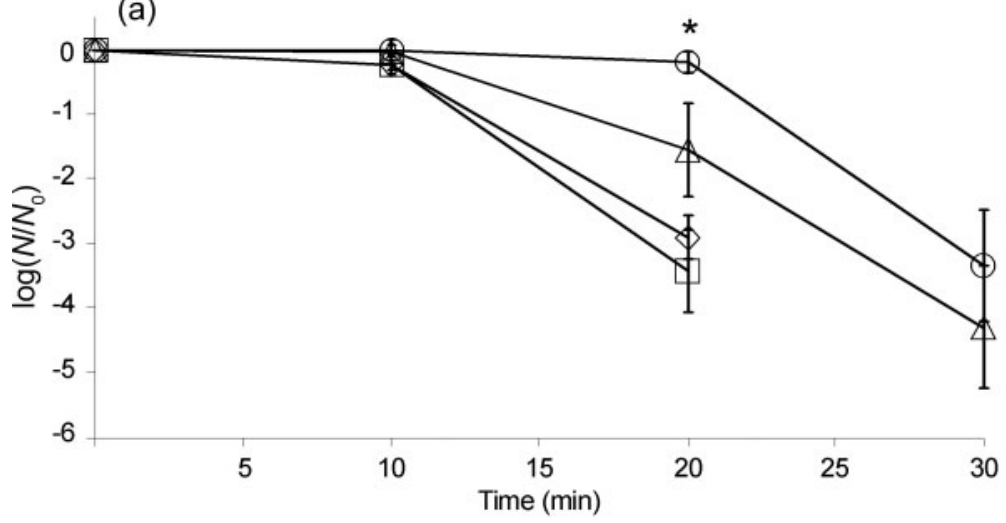

(b)

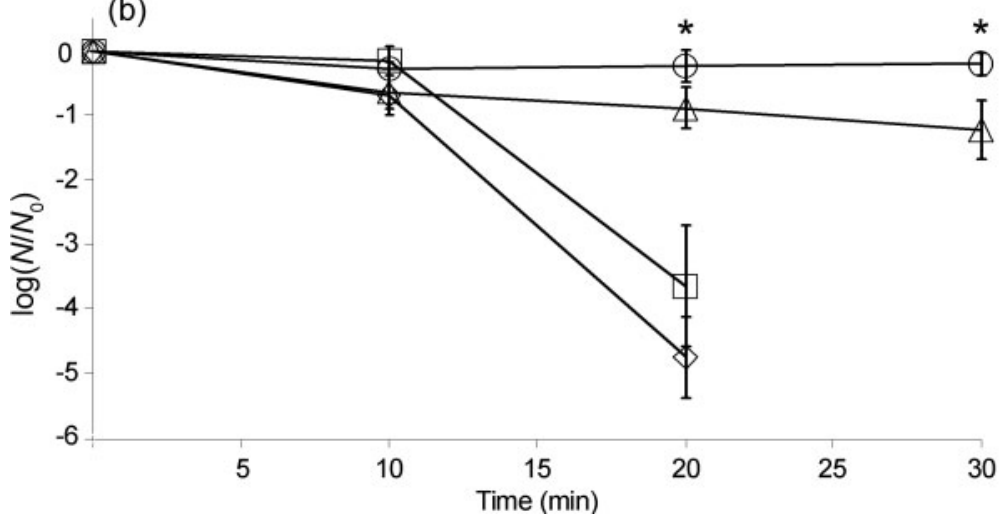

Fig. 3. Effect of oxygen utilization on $\mathrm{H}_{2} \mathrm{O}_{2}$ resistance of $L b$. plantarum WCFS1 grown in MRS medium without added manganese. The graphs show the survival of exponential-phase (a) and stationary-phase (b) cells grown under fermentative $(\diamond)$, aerobic $(\square)$, aerobic with haem $(\triangle)$ and respiratory $(\bigcirc)$ conditions at $30{ }^{\circ} \mathrm{C}$ after exposure to $0.2 \%(\mathrm{w} / \mathrm{v}$, exponential phase) or $0.5 \%$ (w/v, stationary phase) $\mathrm{H}_{2} \mathrm{O}_{2}$. Samples were taken at $0,10,20$ and $30 \mathrm{~min}$, and the c.f.u. $\mathrm{ml}^{-1}$ were counted and expressed as $\log \left(N / N_{0}\right)$. *, Significantly different from values for all other conditions $(P<0.05, t$ test $)$.

manganese was observed after $30 \mathrm{~min}$ exposure to $0.5 \%$ (w/v) $\mathrm{H}_{2} \mathrm{O}_{2}$ compared with stationary-phase cells of the fermentative and aerobic cultures $(P<0.05, t$ test) (Fig. $2 \mathrm{~b})$.

Notably, exponential-phase respiratory-grown cells in MRS without manganese showed higher survival after exposure for 20 min to $0.2 \%$ (w/v) $\mathrm{H}_{2} \mathrm{O}_{2}$ compared with exponential-phase cells of the fermentative, aerobic, and aerobic with haem cultures $(P<0.05, t$ test) (Fig. 3a). Also, stationary-phase cells of the respiratory-grown cultures at 20 min were more resistant to $0.5 \%(\mathrm{w} / \mathrm{v}) \mathrm{H}_{2} \mathrm{O}_{2}$ compared with stationary-phase cells from the other conditions $(P<0.05, t$ test) (Fig. 3b). Interestingly, exponential-phase cells of the respiratory-grown cultures after $20 \mathrm{~min}$ and of the other conditions after $10 \mathrm{~min}$ with added manganese were more sensitive to $\mathrm{H}_{2} \mathrm{O}_{2}$ exposure than cells derived from cultures without added manganese $(P<0.05, t$ test $)$ (Figs $2 \mathrm{a}$ and $3 \mathrm{a}$ ). These results suggest that respiratory growth results in increased resistance to $\mathrm{H}_{2} \mathrm{O}_{2}$ exposure and that the contribution of manganese is dependent on the growth phase at which the cells were harvested and subsequently tested for resistance. In a separate experiment, the cells were also exposed to plumbagin, a superoxide generator. Exposure of harvested cells from the fermentative, aerobic without and with haem, and respiratory-grown cultures revealed resistance of stationary-phase cells (data not shown), whereas exponentialphase cells grown in the absence of manganese showed higher resistance to plumbagin (see Supplementary Fig. S1, available with the online version of this paper). This is consistent with our data obtained with $\mathrm{H}_{2} \mathrm{O}_{2}$ stress, suggesting that growth at low manganese levels may result in activation of alternative stress resistance mechanisms.

\section{Impact of catalase on growth-mode-dependent $\mathrm{H}_{2} \mathrm{O}_{2}$ resistance}

As catalase is one of the most important enzymes for bacterial resistance against $\mathrm{H}_{2} \mathrm{O}_{2}$, we investigated catalase gene (kat) expression and catalase activity in the different growth conditions (Fig. 4). No differences in expression of kat were observed in exponential-phase cells derived from the different cultures (Fig. 4a). However, except for fermentation conditions, expression of kat was significantly induced in the stationary phase of growth in media without and with added manganese $(P<0.05, t$ test). These results suggest that oxygen influx (shaking), which is the common factor that is absent during fermentative growth, results in the induction of kat expression. Catalase activity was also determined for the different growth conditions. In exponential-phase cells grown under the aerobic with haem and respiratory conditions, catalase activity was significantly higher compared with the fermentative and aerobic growth conditions without and with added manganese $(P<0.05, t$ test) (Fig. $4 \mathrm{~b})$. Similar results were observed for catalase activity in stationary-phase cells, although the catalase activity in cells from the aerobic with haem and respiratory growth conditions was significantly 


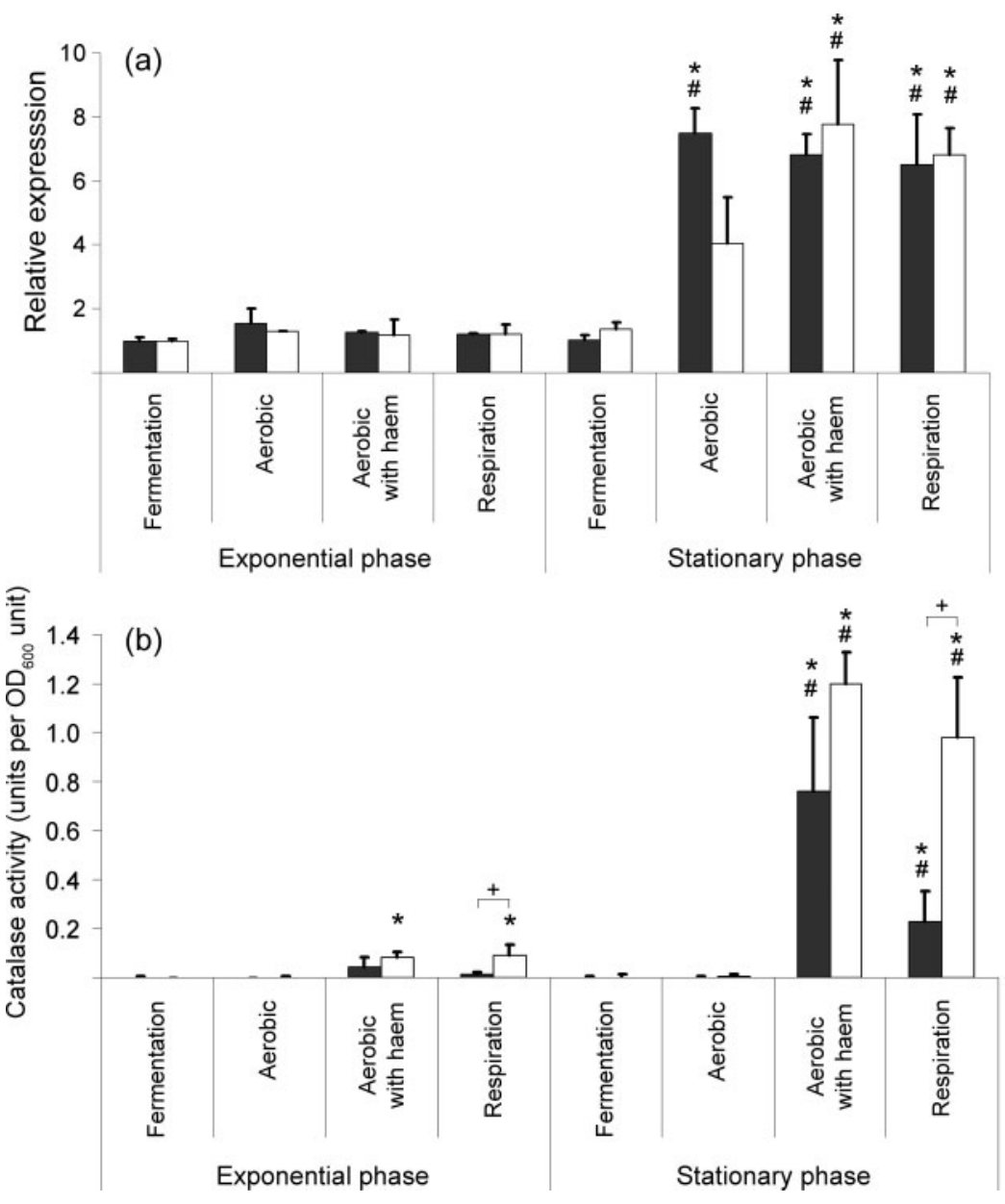

\begin{abstract}
Fig. 4. Effect of oxygen utilization and manganese addition on catalase expression and activity in Lb. plantarum WCFS1. The graphs show the relative catalase gene (kat) expression (a) and catalase activity (b) of cells grown in MRS medium with (black bars) and without (white bars) added manganese, under fermentative, aerobic, aerobic with haem and respiratory conditions at $30{ }^{\circ} \mathrm{C}$. *, Significantly different from values for exponential-phase cells grown statically with added manganese; \#, significantly different from exponentialphase cells; + , significant difference between values with and without added manganese $(P<0.05, t$ test $)$.
\end{abstract}

induced compared with activity in exponential-phase cells $(P<0.05, t$ test $)$. However, catalase activity in respiratorygrown cells was similar to that in cells grown aerobically with haem, although in most conditions higher resistance against hydrogen peroxide was observed for respiratorygrown cells. These results suggest that, besides catalase, additional factors might be involved in the resistance of respiratory-grown cells to $\mathrm{H}_{2} \mathrm{O}_{2}$ exposure. Also, for the respiratory-grown cultures catalase activity was higher without manganese added for both exponential- and stationary-phase cells compared with cultures grown with added manganese $(P<0.05, t$ test). These results indicate that manganese availability affects haem-dependent catalase activity and $\mathrm{H}_{2} \mathrm{O}_{2}$ resistance of exponential- and stationary-phase cells of $L b$. plantarum WCFS1 to different extents.

\section{DISCUSSION}

We investigated the growth performance and oxidative stress resistance of $L b$. plantarum WCFS1 under respiratory, aerobic with haem, aerobic, and fermentative growth conditions in MRS medium without and with added manganese. Previously, it has been shown that respiratory growth of $L b$. plantarum resulted in higher biomass production and a higher final $\mathrm{pH}$ compared with fermentative growth (Brooijmans et al., 2009a, b). These results are in agreement with our observations for respiratory growth in the presence of manganese. However, no differences in $L b$. plantarum WCFS1 biomass production or final $\mathrm{pH}$ were observed with cultures grown without added manganese, and final cell densities were significantly lower than those reached with added manganese. It has previously been shown that $L b$. plantarum requires high concentrations of manganese to reach optimum growth in fermentative and in aerobic conditions without haem (Archibald \& Duong, 1984; Groot et al., 2005). As Lb. plantarum WCFS1 was capable of growth in MRS broth without added manganese, it is possible that trace amounts of manganese were introduced with the yeast extract, beef extract and/or peptone fractions added to the MRS medium.

To investigate the influence of the different growth modes on oxidative stress resistance, exponential- and stationaryphase cells of the different cultures were exposed to $\mathrm{H}_{2} \mathrm{O}_{2}$. In general, both exponential- and stationary-phase cells of the respiratory-grown cultures showed highest resistance against $\mathrm{H}_{2} \mathrm{O}_{2}$. Lb. plantarum WCFS1 contains a specific 
haem-dependent $\mathrm{H}_{2} \mathrm{O}_{2}$-degrading catalase (Kleerebezem et al., 2003; Brooijmans et al., 2009a, b), but not an additional manganese-dependent catalase, as described for other lactobacilli (Kono \& Fridovich, 1983a). Therefore, we investigated the role of this haem-dependent catalase in the resistance of cells derived from the various growth modes against $\mathrm{H}_{2} \mathrm{O}_{2}$. Higher expression and activity of catalase were indeed observed under respiratory growth compared with fermentative growth. Expression of kat appeared to be specifically dependent on induced oxygen influx (shaking), while catalase activity was dependent on the addition of haem to the growth medium. Nevertheless, the respiratory-grown cultures tended to be more resistant to $\mathrm{H}_{2} \mathrm{O}_{2}$ than aerobic with haem cultures, which showed similar levels of catalase expression and activity. However, catalases convert $\mathrm{H}_{2} \mathrm{O}_{2}$ to water and oxygen, thereby increasing intracellular oxygen levels, which in turn may cause oxidative damage. The increased resistance to $\mathrm{H}_{2} \mathrm{O}_{2}$ of the respiratory-grown cultures compared with those grown aerobically with haem might therefore be related to the rapid consumption of oxygen by the active ETC (Fig. 5), as previously suggested for increased long-term survival of respiratory-grown Lc. lactis cultures compared with aerobic cultures (Rezaïki et al., 2004). Alternatively, increased resistance of the respiratory-grown $\mathrm{Lb}$. plantarum culture might be related to the induction of oxidative stress resistance mechanisms as a result of formation of ROS, such as superoxide radicals, due to leakage of electrons from ETC intermediates (Imlay \& Fridovich, 1991; GonzálezFlecha \& Demple, 1995; Kohanski et al., 2007). Previous studies with fermentative and aerobically grown $L b$. plantarum showed that cells accumulate high levels of intracellular manganese to scavenge for superoxide radicals, as this bacterium does not contain a SOD enzyme that could

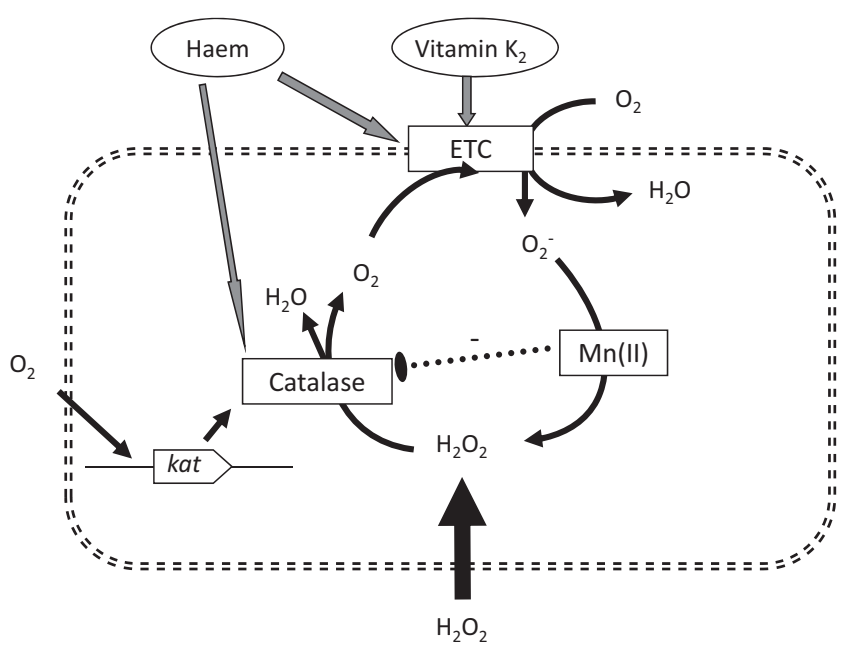

Fig. 5. Schematic representation of the effect of oxygen utilization, haem and manganese availability on (haem-dependent) catalase expression/activity and $\mathrm{H}_{2} \mathrm{O}_{2}$ resistance of $L b$. plantarum WCFS1. See text for details. prevent the damaging activities of these oxidizing radicals (Archibald \& Fridovich, 1981). In our study, stationaryphase cells grown with high manganese showed higher resistance to $\mathrm{H}_{2} \mathrm{O}_{2}$ than cells grown with low manganese, with haem-catalase-producing aerobic with haem and respiratory-grown cells showing the highest resistance. However, exponential-phase cells of Lb. plantarum WCFS1 grown without added manganese showed higher resistance to $\mathrm{H}_{2} \mathrm{O}_{2}$ than exponential-phase cultures grown with added manganese, with again the haem-dependent catalaseproducing aerobic with haem and respiratory cultures showing the highest resistance. Notably, a similar observation was made for cells exposed to plumbagin, a superoxide generator. The low manganese levels might activate other $L b$. plantarum oxidative stress resistance mechanisms, including thioredoxin reductases, glutathione reductases, NADH oxidases and $\mathrm{NADH}$ peroxidases (Murphy \& Condon, 1984; Kleerebezem et al., 2003; Serrano et al., 2007). In addition, a role for the alternative sigma factor $54(r p o N)$ in regulating the mannose phosphotransferase system in $\mathrm{H}_{2} \mathrm{O}_{2}$ resistance has recently been identified (Stevens et al., 2010).

In conclusion, this study has shown that respiratory growth of $\mathrm{Lb}$. plantarum results in increased cell densities and increased oxidative stress resistance. Furthermore, a growth-phase-dependent influence of manganese levels on $\mathrm{H}_{2} \mathrm{O}_{2}$ and plumbagin resistance was detected. These results may be relevant for industrial applications and may provide a basis to assess the impact of respiratory-like growth on the robustness of starter bacteria and probiotics.

\section{REFERENCES}

Abriouel, H., Herrmann, A., Stärke, J., Yousif, N. M., Wijaya, A., Tauscher, B., Holzapfel, W. \& Franz, C. M. (2004). Cloning and heterologous expression of hematin-dependent catalase produced by Lactobacillus plantarum CNRZ 1228. Appl Environ Microbiol 70, 603606.

Archibald, F. S. \& Duong, M. N. (1984). Manganese acquisition by Lactobacillus plantarum. J Bacteriol 158, 1-8.

Archibald, F. S. \& Fridovich, I. (1981). Manganese and defenses against oxygen toxicity in Lactobacillus plantarum. J Bacteriol 145, 442-451.

Brooijmans, R., Smit, B., Santos, F., van Riel, J., de Vos, W. M. \& Hugenholtz, J. (2009a). Heme and menaquinone induced electron transport in lactic acid bacteria. Microb Cell Fact 8, 28.

Brooijmans, R. J., de Vos, W. M. \& Hugenholtz, J. (2009b). Lactobacillus plantarum WCFS1 electron transport chains. Appl Environ Microbiol 75, 3580-3585.

Chapman, H. D. (1966). In Diagnostic Criteria for Plants and Soils, pp. 484-499. Edited by H. D. Chapman. Riverside, CA: Calfornia University Division of Agricultural Science.

Delwiche, E. A. (1961). Catalase of Pedicoccus cerevisiae. J Bacteriol 81, 416-418.

de Man, J. C., Rogosa, M. \& Sharpe, M. E. (1960). A medium for the cultivation of lactobacilli. J Appl Microbiol 23, 130-135.

den Besten, H. M., Mols, M., Moezelaar, R., Zwietering, M. H. \& Abee, T. (2009). Phenotypic and transcriptomic analyses of mildly and 
severely salt-stressed Bacillus cereus ATCC 14579 cells. Appl Environ Microbiol 75, 4111-4119.

Duwat, P., Sourice, S., Cesselin, B., Lamberet, G., Vido, K., Gaudu, P., Le Loir, Y., Violet, F., Loubière, P. \& Gruss, A. (2001). Respiration capacity of the fermenting bacterium Lactococcus lactis and its positive effects on growth and survival. J Bacteriol 183, 4509-4516.

Elkins, C. A. \& Mullis, L. B. (2004). Bile-mediated aminoglycoside sensitivity in Lactobacillus species likely results from increased membrane permeability attributable to cholic acid. Appl Environ Microbiol 70, 7200-7209.

FAO/WHO (2001). Guidelines for the evaluation of probiotics in food. http://www.who.int/foodsafety/fs_management/en/probiotic_ guidelines.pdf

Fiocco, D., Capozzi, V., Goffin, P., Hols, P. \& Spano, G. (2007). Improved adaptation to heat, cold, and solvent tolerance in Lactobacillus plantarum. Appl Microbiol Biotechnol 77, 909-915.

Fuller, R. (1989). Probiotics in man and animals. J Appl Bacteriol 66, 365-378.

Gaudu, P., Vido, K., Cesselin, B., Kulakauskas, S., Tremblay, J., Rezaïki, L., Lamberet, G., Sourice, S., Duwat, P. \& Gruss, A. (2002). Respiration capacity and consequences in Lactococcus lactis. Antonie van Leeuwenhoek 82, 263-269.

González-Flecha, B. \& Demple, B. (1995). Metabolic sources of hydrogen peroxide in aerobically growing Escherichia coli. J Biol Chem 270, 13681-13687.

Groot, M. N., Klaassens, E., de Vos, W. M., Delcour, J., Hols, P. \& Kleerebezem, M. (2005). Genome-based in silico detection of putative manganese transport systems in Lactobacillus plantarum and their genetic analysis. Microbiology 151, 1229-1238.

Imlay, J. A. \& Fridovich, I. (1991). Superoxide production by respiring membranes of Escherichia coli. Free Radic Res Commun 12, 59-66.

Imlay, J. A. \& Linn, S. (1988). DNA damage and oxygen radical toxicity. Science 240, 1302-1309.

Ingham, C. J., Beerthuyzen, M. \& van Hylckama Vlieg, J. (2008). Population heterogeneity of Lactobacillus plantarum WCFS1 microcolonies in response to and recovery from acid stress. Appl Environ Microbiol 74, 7750-7758.

Kleerebezem, M., Boekhorst, J., van Kranenburg, R., Molenaar, D., Kuipers, O. P., Leer, R., Tarchini, R., Peters, S. A., Sandbrink, H. M. \& other authors (2003). Complete genome sequence of Lactobacillus plantarum WCFS1. Proc Natl Acad Sci U S A 100, 1990-1995.

Knauf, H. J., Vogel, R. F. \& Hammes, W. P. (1992). Cloning, sequence, and phenotypic expression of katA, which encodes the catalase of Lactobacillus sake LTH677. Appl Environ Microbiol 58, 832-839.

Kohanski, M. A., Dwyer, D. J., Hayete, B., Lawrence, C. A. \& Collins, J. J. (2007). A common mechanism of cellular death induced by bactericidal antibiotics. Cell 130, 797-810.

Kono, Y. \& Fridovich, I. (1983a). Functional significance of manganese catalase in Lactobacillus plantarum. J Bacteriol 155, 742-746.
Kono, Y. \& Fridovich, I. (1983b). Isolation and characterization of the pseudocatalase of Lactobacillus plantarum. J Biol Chem 258, 60156019.

Labanauskas, C. K. (1966). In Diagnostic Criteria for Plants and Soils, pp. 264-285. Edited by H. D. Chapman. Riverside, CA: Calfornia University Division of Agricultural Science.

Marco, M. L., Bongers, R. S., de Vos, W. M. \& Kleerebezem, M. (2007). Spatial and temporal expression of Lactobacillus plantarum genes in the gastrointestinal tracts of mice. Appl Environ Microbiol 73, 124-132.

Meijerink, M., van Hemert, S., Taverne, N., Wels, M., de Vos, P., Bron, P. A., Savelkoul, H. F., van Bilsen, J., Kleerebezem, M. \& Wells, J. M. (2010). Identification of genetic loci in Lactobacillus plantarum that modulate the immune response of dendritic cells using comparative genome hybridization. PLOS ONE 5, e10632.

Mille, Y., Beney, L. \& Gervais, P. (2005). Compared tolerance to osmotic stress in various microorganisms: towards a survival prediction test. Biotechnol Bioeng 92, 479-484.

Murphy, M. G. \& Condon, S. (1984). Correlation of oxygen utilization and hydrogen peroxide accumulation with oxygen induced enzymes in Lactobacillus plantarum cultures. Arch Microbiol 138, 44-48.

Reuther, W. \& Labanauskas, C. K. (1966). In Diagnostic Criteria for Plants and Soils, pp. 157-175. Edited by H. D. Chapman. Riverside, CA: Calfornia University Division of Agricultural Science.

Rezaïki, L., Cesselin, B., Yamamoto, Y., Vido, K., van West, E., Gaudu, P. \& Gruss, A. (2004). Respiration metabolism reduces oxidative and acid stress to improve long-term survival of Lactococcus lactis. Mol Microbiol 53, 1331-1342.

Serrano, L. M., Molenaar, D., Wels, M., Teusink, B., Bron, P. A., de Vos, W. M. \& Smid, E. J. (2007). Thioredoxin reductase is a key factor in the oxidative stress response of Lactobacillus plantarum WCFS1. Microb Cell Fact 6, 29.

Stevens, M. J., Molenaar, D., de Jong, A., de Vos, W. M. \& Kleerebezem, M. (2010). Involvement of the mannose phosphotransferase system of Lactobacillus plantarum WCFS1 in peroxide stress tolerance. Appl Environ Microbiol 76, 3748-3752.

van de Guchte, M., Serror, P., Chervaux, C., Smokvina, T., Ehrlich, S. D. \& Maguin, E. (2002). Stress responses in lactic acid bacteria. Antonie van Leeuwenhoek 82, 187-216.

Vaughan, E. E., Heilig, H. G., Ben-Amor, K. \& de Vos, W. M. (2005). Diversity, vitality and activities of intestinal lactic acid bacteria and bifidobacteria assessed by molecular approaches. FEMS Microbiol Rev 29, 477-490.

Vesa, T., Pochart, P. \& Marteau, P. (2000). Pharmacokinetics of Lactobacillus plantarum NCIMB 8826, Lactobacillus fermentum KLD, and Lactococcus lactis MG 1363 in the human gastrointestinal tract. Aliment Pharmacol Ther 14, 823-828.

Wang, D., Du, X. \& Zheng, W. (2008). Alteration of saliva and serum concentrations of manganese, copper, zinc, cadmium and lead among career welders. Toxicol Lett 176, 40-47.

Edited by: P. Zuber 